\title{
High frequency of the CCR5delta32 variant among individuals from an admixed Brazilian population with sickle cell anemia
}

J.A.B. Chies and M.H. Hutz
Departamento de Genética, Universidade Federal do Rio Grande do Sul, Porto Alegre, RS, Brasil

\author{
Correspondence \\ J.A.B. Chies \\ Departamento de Genética, UFRGS \\ Av. Bento Gonçalves, 9500 \\ Caixa Postal 15053 \\ 91501-970 Porto Alegre, RS \\ Brazil \\ Fax: +55-51-339-2011 \\ E-mail: jabchies@terra.com.br \\ Research supported by CNPq and \\ FAPERGS.
}

Received October 29, 2001 Accepted September 23, 2002

\begin{abstract}
Homozygous sickle cell disease (SCD) has a wide spectrum of clinical manifestations. In Brazil, the main cause of death of individuals with SCD is recurrent infection. The CCR5 $\triangle 32$ allele, which confers relative resistance to macrophage-tropic HIV virus infection, probably has reached its frequency and world distribution due to other pathogens that target macrophage in European populations. In the present investigation a relatively higher prevalence (5.1\%) of the CCR5 32 allele was identified, by PCR amplification using specific primers, in 79 SCD patients when compared to healthy controls (1.3\%) with the same ethnic background (Afro-Brazilians). Based on a hypothesis that considers SCD as a chronic inflammatory condition, and since the CCR5 chemokine receptor is involved in directing a Th1-type immune response, we suggest that a Th1/Th2 balance can influence the morbidity of SCD. If the presence of the null CCR $5 \Delta 32$ allele results in a reduction of the chronic inflammation state present in SCD patients, this could lead to differential survival of SCD individuals who are carriers of the CCR5 532 allele. This differential survival could be due to the development of less severe infections and consequently reduced or less severe vaso-occlusive crises.
\end{abstract}

The Brazilian population is of heterogeneous ethnic origin and is unevenly distributed in a country of continental dimensions. In addition to the Portuguese who settled the country in the beginning of the 16th century, from the 16th to the 19th century 3 million black slaves were brought to Brazil. Also, from the second half of the 19th century to the end of World War II, Brazil received almost 5 million immigrants, mainly from Italy, Spain and Germany. All of these groups have been gradually intermixing and the country's 1996 population was estimated to be composed of $55.2 \%$ persons of European
Key words

- CCR5 432

- Sickle cell anemia

- Inflammation extraction, $6 \%$ of predominantly African extraction, $38.2 \%$ admixed, $0.4 \%$ Asiatic, and $0.2 \%$ native Indians ( 1 ).

Homozygous sickle cell disease (SCD) has a wide spectrum of clinical manifestations which vary from an almost asymptomatic condition to severe illness despite the fact that all subjects with this disease have the same base change in their DNA (2). The source of this variation is partly environmental, but a large part of this variability derives from the presence of genetic modulators linked or unlinked to the $\beta$-globin gene cluster which are not fully understood (2). 
SCD is the most common single gene disorder in Brazil. The $\mathrm{HBB}^{*} \mathrm{~S}$ allele frequency varies in the country, from $2 \%$ in the general population from the south and southeast to $7.5 \%$ in the northeast. The clinical course of SCD in Brazil has been described (3), and significant clinical diversity has been demonstrated, ranging from death in infancy to barely symptomatic patients, with death being mainly due to recurrent infections (the mean age at death in this study was 16 years). The $\beta$ chemokine receptor CCR5 belongs to the heterotrimeric GTP-binding protein $(\mathrm{G}$ protein)-coupled receptor superfamily (4). It is the major cellular receptor for RANTES, MIP- $1 \alpha$ and MIP-1ß as well as an efficient co-receptor for macrophage-tropic isolates of HIV-1 (5). This molecule is present only in certain cell types, specifically lymphocytes and dendritic cells, driving an immune response involving a Th1 cytokine pattern (6). This chemokine receptor is encoded by the CMBKR5 locus located on chromosome 3. The mutant allele CCR5 $\Delta 32$, which leads to truncation and loss of the receptor on the cell surface, is remarkable because homozygous individuals are resistant to macrophagetropic HIV-1 lineage infection (7).

A genotype survey in several world populations showed that the CCR5 $\Delta 32$ allele is frequent in Caucasoids whereas it is rare or absent in the other major ethnic groups, such as native African and Amerindians $(8,9)$. It was suggested that the CCR5 32 allele has rapidly increased in frequency in Europe due to a strong selective pressure, possibly by a pathogen that targets macrophages, like Yersinia pestis, Shigella, Salmonella or Mycobacterium tuberculosis (8).

In Brazil, infectious diseases are still highly prevalent and infant mortality is high even in the most developed centers. Nevertheless, the number of persons with SCD who reach adult age is similar to that observed in North America (3). Therefore, we asked whether in this admixed population the CCR5 $\triangle 32$ allele would confer resistance against severe recurrent infections contributing to the differential survival of SCD patients.

Our study was conducted on 79 unrelated SCD patients. The samples were collected from patients regularly followed up at public institutions from two cities in the south and northeast of Brazil (Porto Alegre and Recife, respectively). A total of 112 healthy African-derived Brazilians from the south and the southeast (Porto Alegre and Rio de Janeiro) were typed as controls. To establish a local population baseline, a sample of 102 southern European-derived Brazilians with no evidence of miscegenation was also studied. Informed consent was obtained from all subjects. SCD phenotypes were identified by standard procedures as previously described (3). All individuals included in the SCD group were HbS homozygotes. CCR5 typing was performed by PCR using specific primers (CCR5a 5'-GGTCTTCATTACACC TGC-3' and CCR5b 5'-AGGATTCCCGAG TAGCAGATG-3') under the following conditions: $1 \mu \mathrm{l}$ of DNA $(0.2-0.5 \mu \mathrm{g}), 2.5 \mu \mathrm{l}$ of $10 \mathrm{X}$ buffer containing $30 \mathrm{mM} \mathrm{MgCl}_{2}, 0.2 \mu \mathrm{l}$ Taq DNA polymerase (CENBIOT $5 \mathrm{U} / \mu \mathrm{l})$, and $10 \mathrm{mM}$ dNTP and 10 pmol of each primer (total reaction volume $25 \mu \mathrm{l}$ ). Each sample was subjected to 40 cycles of $1 \mathrm{~min}$ at $94^{\circ} \mathrm{C}, 1 \mathrm{~min}$ at $60^{\circ} \mathrm{C}$ and $1 \mathrm{~min}$ at $72^{\circ} \mathrm{C}$. The PCR product was subjected to electrophoresis on $3 \%$ agarose gel containing ethidium bromide and was visualized by UV irradiation. Amplification of the normal allele generates a 137-bp band while the CCR5 $\Delta 32$ allele generates a 105-bp band.

Allele frequencies were determined by counting. Genotype distributions were analyzed using contingency tables and the Fisher test. Hardy-Weinberg equilibrium was tested using a chi-square goodness of fit test. The relative genotype frequencies of the CCR5 polymorphism in the five populations investigated are given in Table 1. The observed frequencies were in Hardy-Weinberg equilibrium in all populations. The prevalence of 
the CCR5 532 allele in the southern European-derived Brazilian population investigated was $4.4 \%$. The prevalence of the CCR5 $\triangle 32$ allele was described as $3.5 \%$ in an urban Brazilian southeast population (10) and, more recently, also in southeast Brazilian Caucasoids, as 5.3\% (11). In the populations from the Mediterranean area with whom European-derived Brazilians share common ancestors, this frequency ranged from 4 to $9 \%(8)$.

In healthy African Brazilians, the CCR5 $\triangle 32$ allele was identified in $1.3 \%$ of the chromosomes investigated (Table 1). In global surveys this allele was absent in African populations (8), but although originally restricted to Caucasoid individuals, its presence among African Brazilian individuals can be easily explained by European gene flow into these populations of African origin. The prevalence observed herein is also similar to that reported for Afro-Americans $1.7 \%$ (12). However, in SCD patients, who are also of African ancestry, the CCR $5 \Delta 32$ allele was present in $5.1 \%$ of the chromosomes. Although the difference between healthy Afro-Brazilians and SCD patients is of borderline significance ( $\mathrm{P}=0.05)$, the prevalence of heterozygous individuals in both of these samples (Recife and Porto Alegre) was three times higher in the SCD group than in the controls. The age of the 79 SCD patients ranged from 2 to 65 years (mean 18.7) and the age of CCR $5 \Delta 32$ heterozygotes ranged from 12 to 35 years (mean 26.2)

Two explanations are possible for our observations: a) the higher frequency of the CCR5 $\triangle 32$ allele in SCD patients is a chance result due to the small sample size or to a higher degree of admixture with other ethnic groups, or b) in this admixed population, the CCR5 52 allele confers an advantage to SCD patients.

Considering previous data and the degree of admixture in the groups analyzed, the first explanation is rather improbable. Although it is certain that the CCR5 $\Delta 32$ allele is present in African Brazilian populations due to gene flow since this allele is absent in the native African population from whom they descend, the phenomenon of gene flow alone cannot account for the differences observed between SCD patients and controls. Since our sample of SCD individuals was already screened for the APOE gene (13) and for the TCRBV18 and TCRBV3S1 gene segments (data not shown) without significant differences from the control healthy individuals, the discrepancy in CCR $5 \Delta 32$ frequencies between the cases and controls should then reflect an advantage. The CCR5 $\triangle 32$ allele is not autochthonous to the New World. Data from our group indicate its absence in South American native populations (data not shown) and absence of this

\begin{tabular}{|c|c|c|c|c|c|c|c|}
\hline & \multicolumn{3}{|c|}{ Sickle cell anemia patients } & \multicolumn{3}{|c|}{ African Brazilians } & \multirow[t]{2}{*}{ European Brazilians } \\
\hline & $\begin{array}{l}\text { Recife } \\
\text { (53) }\end{array}$ & $\begin{array}{c}\text { Porto } \\
\text { Alegre } \\
\text { (26) }\end{array}$ & $\begin{array}{l}\text { Total } \\
\text { (79) }\end{array}$ & $\begin{array}{c}\text { Porto } \\
\text { Alegre } \\
(58)\end{array}$ & $\begin{array}{l}\text { Rio de } \\
\text { Janeiro } \\
\quad(54)\end{array}$ & $\begin{array}{l}\text { Total } \\
\text { (112) }\end{array}$ & \\
\hline Normal & 91 & 88 & 90 & 98 & 96 & 97 & 91 \\
\hline CCR5 $\Delta 32$ heterozygotes & 9 & 12 & 10 & 2 & 4 & 3 & 9 \\
\hline CCR5 432 allele frequency & 4.7 & 5.8 & 5.1 & 0.8 & 1.9 & 1.3 & 4.4 \\
\hline
\end{tabular}

The total number of individuals from each population is given in parentheses. Both genotype and CCR5 $\triangle 32$ frequencies are given as percentage in each population. 
variant was also reported in indigenous populations of the Brazilian Amazon (9). Thus, the native South American groups that also contribute to the gene pool of the present Brazilian populations could not contribute to elevating the frequency of the CCR $5 \Delta 32$ allele. This observation is especially important in the SCD group from Recife (Northeast of Brazil) which is trihybrid. Also, similar allelic frequencies were observed in both SCD groups. The two samples screened for the CCR5 $\triangle 32$ allele are geographically isolated. Given the low frequency of this allele in the control Afro-Brazilian populations as well as in an admixed Afro-American population (12), a three-fold increase present in SCD patients (even considering the existence of admixture) seems to be quite important. This situation suggests that the higher frequency of the CCR5 32 allele in SCD patients is the result of some other factor besides gene flow.

Therefore, we suggest that the higher frequency of the CCR $5 \Delta 32$ allele among SCD individuals could be due to an increased life span as a result of reduced SCD morbidity, meaning less frequent or less severe infections in CCR5 $\Delta 32$ carriers. As HIV infection is not a major problem among SCD patients in Brazil, the resistance conferred by the CCR $5 \Delta 32$ allele against macrophagetropic HIV-1 lineages is probably not this factor. Nevertheless, one of the major causes of death among SCD patients is recurrent infection and there are speculations about the role of the CCR5 32 allele in protecting against other bacterial or viral infections $(14,15)$. As the physiological ligands for CCR5 are RANTES, MIP- $1 \alpha$ and MIP-1ß, chemokines involved in macrophage adhesion and migration pathways, it should be useful to analyze these properties in SCD individuals who are also carriers of the CCR5 32 allele.

On the basis of a series of observations, SCD could be considered to be a disease involving a chronic inflammatory state. For example, the description of occasional elevation of plasma MIP- $1 \alpha$ levels in SCD patients suggests that the development of an inflammatory response is an important event during the vaso-occlusive crisis (16). It was shown that hypoxia/reoxygenation causes an inflammatory response in transgenic sickle mice but not in normal mice (17). If SCD is a chronic inflammatory disease, patients with the CCR5 32 allele would benefit from the development of inflammatory responses at low levels. In an analysis of mannose-binding protein (a lectin involved in innate immunity) variants in children with SCD, it was observed that the majority of individuals presenting mannose-binding protein variants belong to a group that does not present severe and recurrent infections (18). Like our data, these results may indicate that SCD individuals who develop inflammatory responses at low levels will present a less severe spectrum of clinical manifestations. In a recent article (19) we provided an extensive review of data supporting this hypothesis.

The explanation for the high CCR5 $\Delta 32$ allele frequency found among SCD patients could be related to the type of immune response induced by the CCR5 receptor. The CCR5 molecule is normally expressed in T lymphocytes and dendritic cells, driving a preferential Th1 immune response (6). Since the Th1 immune response is associated with inflammation, we propose that the advantage conferred to SCD patients by the nonfunctional CCR5 32 allele relies in less effective Th1 responses, consequently leading to a less severe inflammatory state and a less severe (or inexistent) vaso-occlusive crisis. Thus, it would be interesting to determine if there is a preferential Th2 cytokine pattern in the $\mathrm{T}$ cell responses of SCD patients carrying the CCR5 $\Delta 32$ allele. Also considering a Th1xTh2 cytokine pattern, it has been suggested that the mechanism of protection from falciparum malaria by red cell genetic disorders could involve a switch to a balanced 
Th1/Th2 cytokine production mode (20). Although in the present study we did not deal with falciparum malaria but with a condition that predisposes to a variety of infections, the idea of a Th1/Th2 balance regulating the morbidity of SCD is attractive and involves the necessity of an equilibrium between immune responses against pathogens and low levels of inflammatory responses (low levels of Th1 responses, for instance) to avoid the occurrence of vaso-occlusive crises. The intriguing observation of a correlation between CCR5 $\triangle 32$ allele frequency and SCD strongly suggests the participation of the immune system in the pathophysiology of SCD.

\section{References}

1. Callegari-Jacques SM \& Salzano FM (1999). Brazilian Indian/non Indian interactions and their effects. Ciência e Cultura, 51: 166-174.

2. Nagel RL (1991). Severity, pathobiology, epistatic effects and genetic markers in sickle cell anemia. Seminars in Hematology, 28: 180-201.

3. Hutz MH \& Salzano FM (1983). Sickle cell anemia in Rio de Janeiro, Brazil: Demographic, clinical and laboratory data. Brazilian Journal of Medical and Biological Research, 16: 219-226.

4. Raport CJ, Gosling J, Schweickart VL, Gray PW \& Charo IF (1996). Molecular cloning and functional characterization of a novel human CC chemokine receptor (CCR5) for RANTES, MIP-1beta and MIP1alpha. Journal of Biological Chemistry, 271: 17161-17166.

5. Dragic T, Litwin V, Allaway GP, Martin SR, Huang Y, Nagashima KA, Cayanan C, Maddon PJ, Koup RA, Moore JP \& Paxton WA (1996). HIV-1 entry into CD4+ cells is mediated by the chemokine receptor CC-CKR-5. Nature, 381: 667-673.

6. Loetscher P, Uguccioni, M, Bordoli L, Baggiolini M, Moser B, Chizzolini C \& Dayer JM (1998). CCR5 is characteristic of Th1 lymphocytes. Nature, 391: 344-345

7. Zimmerman PA, Buckler-White A, Alkhatib G, Spalding T, Kubofcik J, Combadiere C, Weissman D, Cohen O, Rubbert A, Lam G, Vaccarezza M, Kennedy PE, Kumaraswami V, Giorgi JV, Detels R, Hunter J, Chopek M, Berger EA, Fauci AS, Nutman TB \& Murphy PM (1997). Inherited resistance to HIV-1 infection conferred by an inactivating mutation in CC chemokine receptor 5 - studies in populations with contrasting clinical phenotypes, defined racial background, and quantified risk. Molecular Medicine, 3: 23-26.

8. Stephens JC, Reich DE, Goldstein DB, Shin HD, Smith MW, Carrington M, Winkler C, Huttley GA, Allikmets R, Schriml L, Gerrard B, Malasky M, Ramos MD, Morlot S, Tzetis M, Oddoux C, di Giovine FS, Nasioulas G, Chandler D, Aseev M, Hanson M, Kalaydjieva L, Glavac D, Gasparini P, Kanavakis E, Claustres M, Kambouris M, Ostrer H, Duff G, Baranov V, Sibul H, Metspalu A, Goldman D, Martin N, Duffy D, Schmidtke J, Estivill X, O'Brien SJ \& Dean M (1998). Dating the origin of the CCR5- $\Delta 32$ AIDS-resistance allele by the coalescence of haplotypes. American Journal of Human Genetics, 62: 1507-1515.

9. Leboute AP, de Carvalho MW \& Simoes AL (1999). Absence of the deltaccr5 mutation in indigenous populations of the Brazilian Amazon. Human Genetics, 105: 442-443.

10. Passos Jr GA \& Picanco VP (1998). Frequency of the $\Delta \mathrm{ccr} 5$ deletion allele in the urban Brazilian population. Immunological Letters, 61: 205-207

11. Pereira RW, Pires RE, Duarte APM, Moura RP de, Monteiro E,
Torloni H, Proietti AB, Simpson AJG \& Pena SDJ (2000). Frequency of the CCR5 $\Delta 32$ allele in Brazilians: a study in colorectal cancer and in HTLV-I infection. Genetics and Molecular Biology, 23: 523-526.

12. Dean M, Carrington M, Winkler $C$, Huttley GA, Smith MW, Allikmets R, Goedert JJ, Buchbinder SP, Vittinghoff E, Gomperts E, Donfield S, Vlahov D, Kaslow R, Saah A, Rinaldo C, Detels R \& O'Brien SJ (1996). Genetic restriction of HIV-1 infection and progression to AIDS by a deletion allele of the CKR5 structural gene. Hemophilia growth and developmental study, multicenter AIDS cohort study, Multicenter Hemophilia Cohort Study, San Francisco City Cohort, Alive Study. Science, 273: 1856-1862.

13. Andrade FM, Larrandaburu M, Callegari-Jacques SM, Gastaldo G \& Hutz MH (2000). Association of apolipoprotein E with plasma lipids and Alzheimer's disease in a southern Brazilian population. Brazilian Journal of Medical and Biological Research, 33: 529-537.

14. Meyer L, Magierowska M, Hubert JB, Mayaux MJ, Misrahi M, Le Chenadec J, Debre P, Rouzioux C, Delfraissy JF \& Theodorou I (1999). CCR5 delta32 deletion and reduced risk of toxoplasmosis in persons infected with human immunodeficiency virus type 1. The SEROCO-HEMOCO-SEROGEST Study Groups. Journal of Infectious Diseases, 180: 920-924.

15. Shields PL, Morland CM, Salmon M, Oin S, Hubscher SG \& Adams $\mathrm{DH}$ (1999). Chemokine and chemokine receptor interactions provide a mechanism for selective $\mathrm{T}$ cell recruitment to specific liver compartments within hepatitis C-infected liver. Journal of Immunology, 163: $6236-6243$.

16. Croizat $H$ \& Nagel $R L$ (1999). Circulating cytokines response and the level of erythropoiesis in sickle cell anemia. American Journal of Hematology, 60: 105-115.

17. Kaul DK \& Hebbel RP (2000). Hypoxia/reoxygenation causes inflammatory response in transgenic sickle mice but not in normal mice. Journal of Clinical Investigation, 106: 411-420.

18. Neonato MG, Lu CY, Guilloud-Bataille M, Lapoumerouile C, NabeelJassim H, Dabit G, Girot R, Krishnamoorthy R, Feingold J, Besmond C \& Elion J (1999). Genetic polymorphism of the mannose-binding protein gene in children with sickle cell disease: identification of three new variant alleles and relationship to infections. European Journal of Human Genetics, 7: L679-L686.

19. Chies JAB \& Nardi NB (2001). Sickle cell disease: a chronic inflammatory condition. Medical Hypotheses, 57: 46-50.

20. Bayoumi RA (1997). Does the mechanism of protection from falciparum malaria by red cell genetic disorders involve a switch to a balanced TH1/TH2 cytokine production mode? Medical Hypotheses, 48: $11-17$ 